UDC 576

LBC 22.311

\title{
EFFECT OF GLUCOSE ON MORPHOFUNCTIONAL PROPERTIES CHONDROCYTES IN VITRO
}

\author{
Sergey R. Baranov \\ Volgograd State University, Volgograd, Russian Federation \\ Lyudmila V. Derevshchikova \\ Volgograd State University, Volgograd, Russian Federation \\ Alina F. Samitova \\ Volgograd State University, Volgograd, Russian Federation \\ Pavel A. Krylov \\ Volgograd State University, Volgograd, Russian Federation
}

\begin{abstract}
Articular cartilage is a highly specialized dense connective tissue, and can be considered as a composite gel with a relatively low content (5\%) of cells, chondrocytes, embedded in the extracellular matrix. Chondrocytes are the only cell type in articular cartilage and are responsible for the biosynthesis and catabolism of the extracellular matrix. Osteoarthritis, the most common cartilage disease, has many independent risk factors, among which is diabetes mellitus, which allows us to hypothesize that different glucose concentrations have a huge effect on the morfunctional properties of chondrocytes in general and on the formation of osteoarthritis in particular. Despite numerous studies, the question of the effect of glucose on cartilage function is still open. In this regard, the study of morphofunctional changes in chondrocytes under the influence of various glucose concentrations is an urgent problem. The following results were obtained: an increase in the concentration of glucose in cell culture has a positive effect on cell viability and proteoglycan synthesis, but at an external glucose concentration of $25 \mathrm{MM}$, cells die, while the synthesis of proteoglycans remains at a high level. The higher the concentration of glucose in the nutrient medium, the larger the cell size, which is probably due to hypertrophy of chondrocytes. In the future, the results obtained will be useful for understanding the process of hypertrophy and identifying ways to control it, as well as for a detailed study of other biochemical processes.

Key words: morphology, chondrocyte, cell culture, glucose, proteoglycans.

Citation. Baranov S.R., Derevshchikova L.V., Samitova A.F., Krylov P.A. Effect of Glucose on Morphofunctional Properties Chondrocytes in Vitro. Prirodnye sistemy i resursy [Natural Systems and Resources], 2021, vol. 11, no. 2, pp. 12-18. DOI: https://doi.org/10.15688/nsr.jvolsu.2021.2.2

\section{ВЛИЯНИЕ ГЛЮКОЗЫ НА МОРФОФУНКЦИОНАЛЬНЫЕ СВОЙСТВА ХОНДРОЦИТОВ IN VITRO}

\section{Сергей Романович Баранов}

Волгоградский государственный университет, г. Волгоград, Российская Федерация

Людмила Владимировна Деревщикова

Волгоградский государственный университет, г. Волгоград, Российская Федерация 


\section{Алина Фаритовна Самитова}

Волгоградский государственный университет, г. Волгоград, Российская Федерация

\section{Павел Андреевич Крылов}

Волгоградский государственный университет, г. Волгоград, Российская Федерация

Аннотация. Суставной хрящ представляет собой высокоспециализированную плотную соединительную ткань и может рассматриваться как композитный гель с относительно малым содержанием (5 \%) клеток хондроцитов, внедренных во внеклеточный матрикс. Хондроциты являются единственным типом клеток в суставном хряще и отвечают за биосинтез и катаболизм внеклеточного матрикса. Остеоартроз - самое распространенное заболевание хрящей - имеет множество независимых факторов риска, среди которых есть сахарный диабет, что позволяет нам выдвинуть гипотезу об огромном влиянии различных концентраций глюкозы на морфофункциональные свойства хондроцитов в целом и на образование остеоартроза в частности. Несмотря на многочисленные исследования, до сих пор остается открытым вопрос о влиянии глюкозы на функции клеток хряща. В связи с этим изучение морфофункциональных изменений хондроцитов под влиянием различных концентраций глюкозы представляет актуальную задачу. Были получены следующие результаты: повышение концентрации глюкозы в клеточной культуре положительно влияет на жизнеспособность клеток и синтез протеогликанов, но при внешней концентрации глюкозы 25мМ клетки гибнут, при этом синтез протеогликанов остается на высоком уровне. Чем выше концентрация глюкозы в питательной среде, тем больше и размер клеток, что, вероятно, связано с гипертрофией хондроцитов. В дальнейшем полученные результаты пригодятся для понимания процесса гипертрофии и выявления способов ее контроля, а также для подробного изучения других биохимических процессов.

Ключевые слова: морфология, хондроцит, клеточная культура, глюкоза, протеогликаны.

Цитирование. Баранов С. Р., Деревщикова Л. В., Самитова А. Ф., Крылов П. А. Влияние глюкозы на морфофункциональные свойства хондроцитов in vitro // Природные системы и ресурсы. - 2021. - Т. 11, № 2. - C. 12-18. - DOI: https://doi.org/10.15688/nsr.jvolsu.2021.2.2

\section{Введение}

Суставной хрящ представляет собой высокоспециализированную плотную соединительную ткань, и может рассматриваться как композитный гель с относительно малым содержанием (5 \%) клеток, хондроцитов, внедренных во внеклеточный матрикс [7]. Хондроциты являются единственным типом клеток в суставном хряще и отвечают за биосинтез и катаболизм внеклеточного матрикса.

Внеклеточный матрикс гиалинового хряща главным образом состоит из коллагена типа II (COL2A1) и аггрекана (ACAN) [2]. Эти составляющие обеспечивают скольжение внутри суставов, наименьшее трение и повышенный уровень износоустойчивости $[1 ; 6]$. Коллаген типа II является основной макромолекулой внеклеточного матрикса, которая обеспечивает структурную поддержку хряща. Его усиленная деградация и последующая потеря с сопутствующей эрозией хряща является ключевой характеристикой остеоартроза - самого распространенного заболевания хрящей.
Остеоартроз имеет множество независимых факторов риска, среди которых есть сахарный диабет. Это позволяет нам выдвинуть гипотезу, что различные концентрации глюкозы могут оказывать огромное влияние на морфофункциональные свойства хондроцитов в целом и на образование остеоартроза в частности.

Известно, что глюкоза является важной метаболической молекулой для дифференцированных хондроцитов как в постнатальном развитии, так и во взрослом суставном хряще, и является общим структурным предшественником для синтеза гликозаминогликанов внеклеточного матрикса. Было показано, что внеклеточная концентрация глюкозы, как повышенная, так и пониженная, непосредственно влияет на некоторые функции хондроцитов [4].

Несмотря на многочисленные исследования, до сих пор остается открытым вопрос о влиянии глюкозы на функции клеток хряща. В настоящее время подробно изучены аспекты механизма переноса глюкозы белкамитранспортерами в суставном хряще. Также известно, что производные глюкозы, такие как 


\section{ЭКОЛОГИя И БИОЛОГИЯ}

сорбит и диацилглицерин, участвуют в активизации провоспалительных цитокинов, приводя к усилению воспаления при ОА [3]. Однако изучение морфофункциональных изменений хондроцитов под влиянием различных концентрация глюкозы представляет актуальную задачу, ведь это позволит использовать полученные знания в клинических целях.

Цель работы - выявить закономерностей влияния глюкозы на морфофункциональные свойства хондроцитов in vitro.

\section{Материалы и методы}

\section{Выделение клеток}

Содержание животных и выведение их из опыта осуществляли на основе 65 «Правил проведения работ с использованием экспериментальных животных» и Директивы 2010/63/ EU Европарламента и Совета ЕС по охране животных, используемых в научных целях.

Механическим путем происходило выделение хрящевой ткани из тазобедренных и коленных суставов крыс предварительно отделяя от кости и очищая от волокон мышц стерильным скальпелем. Перед тем как перейти к самому выделению клеток хондроцитов, хрящевую ткань стерилизовали, протирая 70 \% этиловым спиртом, а хондроциты выделяли ферментативным путем и для увеличения количества жизнеспособных использовался 3-этапный алгоритм выделения [1].

Суспензию хондроцитов, полученных с трех этапов, переносили дозирующим устройством в 6-лунковые планшеты (6 Well Cell Culture Plate, USA) плотностью $5 * 10^{4}$ клеток/ мл для достижения монослойной культуры, плотно закрывали и обматывали парафильмной пленкой для предотвращения высыхания культуры и ее сохранения.

\section{Культивирование хондроцитов при разной концентрации глюкозы}

Для изучения влияния глюкозы на морфофункциональные характеристики хондроцитов клетки культивировали в среде с добавлением разных концентраций глюкозы, а также при ее отсутствии. Соответственно, полученную суспензию хондроцитов разделили на
4 группы по концентрации глюкозы: $0 ; 1,5 ; 5$; 25 мМ. В каждой группе были хондроциты, выделенные из 6 суставов. Инкубировали в течение 7 дней при $37^{\circ} \mathrm{C}$.

\section{Морфологические методы}

Для выявления морфологических признаков хондроцитов проводили окрашивание по Романовскому - Гимзе. Для определения количества и жизнеспособности клеток использовали методы световой и флуоресцентной микроскопии. Количество живых клеток определяли с помощью окрашивания трипановым синим и использованием камеры Горяева. Для окрашивания смешивали 900 мкл 0,4 \% раствора трипанового синего с 100 мкл клеточной суспензии, то есть разведение 1:10. Тщательно перемешивали и инкубировали в течение 5 минут при комнатной температуре. Далее подсчитали неокрашенные (жизнеспособные) и окрашенные (мертвые) клетки в камере Горяева и определили процент жизнеспособных клеток по формуле (1):

$$
l(\%)=\frac{x l}{x} * 100,
$$

где $l(\%)$ - процент жизнеспособных клеток; $x l$ количество живых (неокрашенных) клеток; $x$ - общее количество клеток.

Расчет числа клеток осуществляли по формуле (2).

$$
X=\left(a * \frac{4000 b}{c}\right) * 1000,
$$

где $a$ - сумма клеток, подсчитанная в 5 больших квадратах сетки; $b$ - разведение исходного субстрата; $c$ - число малых квадратов, в которых производился подсчет; $X$ - количество клеток в 1 мл.

Также для оценки жизнеспособности использовался флуоресцентный метод. В лунки планшета с суспензией хондроцитов добавляли по 2 капли реагента из набора флуоресцентных красителей Cell Viability Imaging Kit, Blue/ Green (Thermofisher scientific). Фиксировали 15 минут. Клетки окрашивались зеленом цветом реагентом NucGreen, который окрашивал только ядра клеток с нарушенной целостнос- 
тью плазматической мембраны и определялся стандартным фильтром GFP, а ядра целых неповрежденных клеток окрашивались NucBlue и обнаруживались при DAPI.

Расчет ядерно-плазматического показателя осуществляли с использование программы ImageJ (США) путем измерения площади всей клетки и площади ядра. Показатель рассчитывался по формуле (3):

$$
P=\frac{S_{\text {об }}}{S_{\text {я }}},
$$

где $P$ - ядерно-цитоплазматический показатель; $S_{\text {об }}$ - общая площадь клетки; $S_{\text {я }}$ площадь ядра.

Протеогликаны в культуральной среде выявляли и количественно подсчитывали с помощью красителя сафранина О. Каплю питательной среды инкубировали в течение 5 мин с красителем в соотношении 1:1. После инкубации наносили на предметное стекло и рассчитывали площадь интенсивно окрашенных участков с использованием программного пакета ImageJ (США).

\section{Статистические методы}

Количественные данные обрабатывали с помощью программы Statistica 12.0 (StatSoft Inc., США) с расчетом показателей, принятых для характеристики непараметрических выборок в медико-биологических исследованиях: нормальность распределения значений, медиана [1-й квартиль, 3-й квартиль] и оценивали достоверность различий выборок [6]. Для анализа различий между выборками использовали критерий Манна-Уитни при достоверности $p=<0.05$.

\section{Результаты и их обсуждения}

Морфологические изменения параметров хондроцитов в условиях изменения концентрации глюкозы в питательной среде описаны в таблице.

Видна положительная зависимость показателя жизнеспособности от интактной группы до концентрации 5 мМ. Однако при концентрации глюкозы 25 мМ жинеспособность клеточной культуры резко падает ниже показателей интактной группы, что свидетельствует о негативном влиянии повышенных концентраций внешней глюкозы на клетки суставного хряща (см. рис. 1). Однако полное отсутствие внешней глюкозы в питательной среде также приводит к снижению жизнеспособности клеток, что, в свою очередь, влияет на количество синтезируемых протеогликанов (см. рис. 2). Последующие нарушения метаболизма в суставном хряще могут привести к развитию такого заболевания, как остеоартроз.

Нами зафиксирована положительная зависимость размеров клетки от концентрации глюкозы в питательной среде. Так как оценка жизнеспособности культуры показала, что при концентрации глюкозы в питательной среде 25 мМ количество живых хондроцитов резко снижается, то есть основания полагать, что мог быть включен процесс, называемый гипетрофией клеток. Также увеличение размеров клетки может быть связано с активным синтезом продуктов, однако анализ содержания количества протеогликанов в каждой лунке говорит об обратном [5]. Исходя из этого, можно предположить, что увеличение клеток

Морфофункциональные свойства хондроцитов in vitro

\begin{tabular}{|l|c|c|c|c|}
\hline \multirow{2}{*}{ Показатель } & \multirow{2}{*}{ Интакт } & \multicolumn{2}{|c|}{ Концентрация глюкозы в питательной среде } \\
\cline { 3 - 5 } & & 1,5 мM & 5 мM & 25 мМ \\
\hline \multirow{2}{*}{ Жизнеспособность } & 0,59 & $0,68 \#$ & $0,80 * \#$ & $0,57 \#$ \\
& {$[0,56 \div 0,75]$} & {$[0,67 \div 0,73]$} & {$[0,79 \div 0,81]$} & {$[0,50 \div 0,65]$} \\
\hline \multirow{2}{*}{ Площадь клеток, мкм } & 96,58 & $139,90 * \#$ & $160,80^{*} \#$ & $189,24^{*} \#$ \\
& {$[84,43 \div 122,02]$} & {$[120,16 \div 160,22]$} & {$[121,32 \div 175,89]$} & {$[159,64 \div 210,14]$} \\
\hline $\begin{array}{l}\text { Ядерно-цитоплазмати- } \\
\text { ческий показатель }\end{array}$ & 0,14 & $0,18^{*}$ & 0,17 & 0,15 \\
\hline $\begin{array}{l}\text { Количество } \\
\text { протеогликанов, мкм }\end{array}$ & {$[0,11 \div 0,17]$} & {$[0,15 \div 0,20]$} & {$[0,14 \div 0,22]$} & {$[0,13 \div 0,19]$} \\
\hline
\end{tabular}

Примечание. * - достоверные различие $p<0,05$ между экспериментальной и интактной группами, \#достоверные различие $p<0,05$ между экспериментальными группами, при использовании критерия Манна Уитни. 


\section{Экология и Биология}

происходит не из-за увеличения синтеза протеогликанов, а из-за активации процессов гибели клеток.

Несмотря на это, глюкоза, наоборот, стимулирует увеличение плотности внутриклеточного матрикса, что тоже не является противоречием, так как относительно интакта в экспериментальной группе с содержанием 5 мМ глюкозы в питательной среде содержалось в 2 раза больше протеогликанов. Более того, при высоких концентрациях внешней глюкозы отмечено уменьшение плотности матрикса, что мы также можем наблюдать на результатах эксперимента (рис. 2).

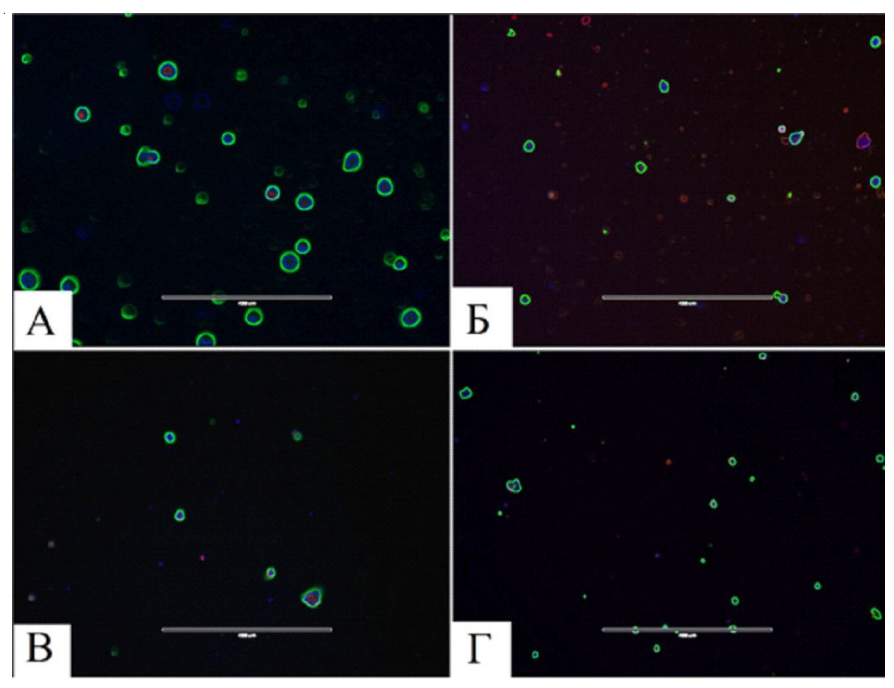

Рис. 1. Результат окрашивания клеточной культуры на жизнеспособность красителем Cell Viability Imaging Kit, Blue/Green ( $A$ - интактная культура клеток суставного хряща; $Б$ - культура клеток, культивируемая с добавлением концентрации глюкозы 1,5 мМ;

$B$ - культура клеток, культивируемая с добавлением концентрации глюкозы 5 мМ; $\Gamma$ - культура клеток, культивируемая с добавлением концентрации глюкозы 25 мМ). Линейка масштаба 400 мкм

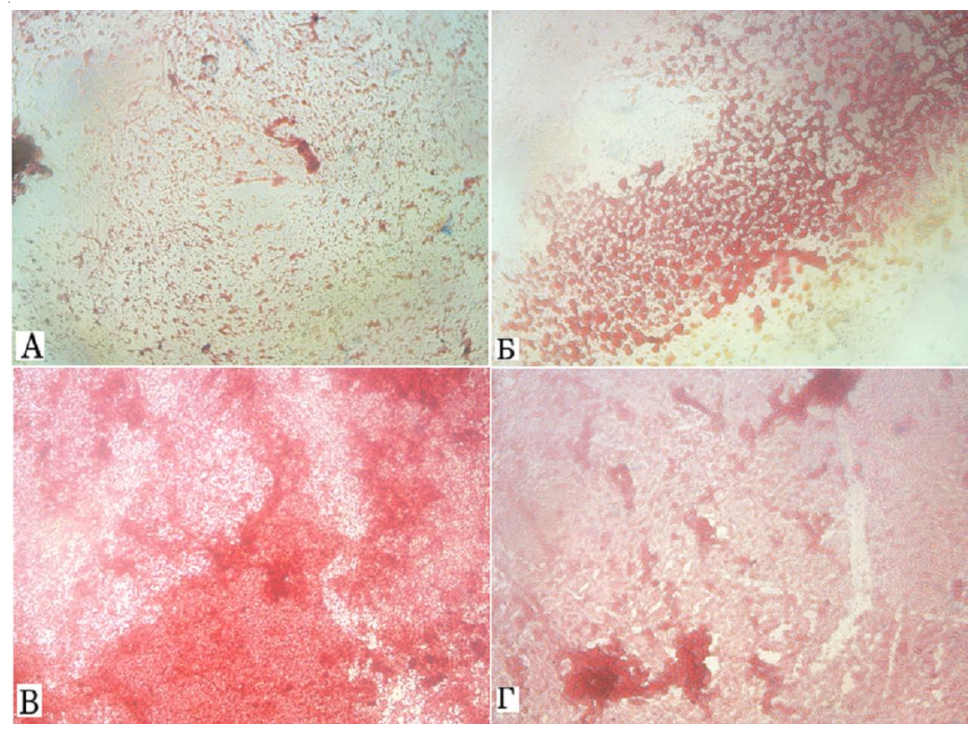

Рис. 2. Окрашивание сафранином О на содержание протеогликанов при разной концентрации глюкозы в питательной среде ( $A$ - интакт; $D$ - количество протеогликанов при культивировании клеток в 1,5 мМ глюкозы; $B$ - количество протеогликанов при содержании в культуре клеток 5мМ глюкозы; $\Gamma$ - количество протеогликанов при глюкозе концентрации $25 \mathrm{MM})$.

Сафранин О имеет свойство связываться с протеогликанами, образуя химическое соединение с ярко-красной окраской 


\section{Заключение}

В результате проведенных исследований можно сделать следующие выводы:

1. Было показано, что повышение концентрации глюкозы в питательной среде оказывает положительное влияние на жизнеспособность хондроцитов, а также на их синтез протеогликанов.

2. Установлено, что при концентрации глюкозы 25 мМ происходит увеличение количества мертвых хондроцитов, при этом не снижается синтез протеогликанов.

3. Выявлена положительная зависимость между концентрацией глюкозы и размером клеток, что может быть связано с гипертрофией хондроцитов.

\section{СПИСОК ЛИТЕРАТУРЫ}

1. Клеточные технологии и тканевая инженерия в лечении дефектов суставной поверхности / Н. Н. Советников [и др.] // Клиническая практика. -2013. - Т. 1, № 13. - С. 52-66.

2. A Small Molecule Promotes Cartilage Extracellular Matrix Generation and Inhibits Osteoarthritis Development / Y. Shi [et al.] // Nat ComMun. - 2019. - Vol. 10, № 1. - P. 1914. - DOI: https://doi.org/10.1038/s41467-019-09839-x.

3. Aiello, F. C. Molecular Links Between Diabetes and Osteoarthritis: The Role of Physical Activity/F. C. Aiello, F. M. Trovato, M. A. Szychlinska // Curr Diabetes Rev. - 2017. - Vol. 13, № 1. - P. 50-58. - DOI: https://doi.org/10.2174/1573399812666151123104352.

4. Akkiraju, H. Role of Chondrocytes in Cartilage Formation, Progression of Osteoarthritis and Cartilage Regeneration / H. Akkiraju, A. Nohe // J Dev Biol. 2015. - Vol. 3, № 4. - P. 177-192. - DOI: https://doi.org/ 10.3390/jdb3040177.

5. Facilitative Glucose Transporters In Articular Chondrocytes. Expression, Distribution and Functional Regulation of GLUT Isoforms by Hypoxia, Hypoxia Mimetics, Growth Factors and Pro-inflammatory Cytokines / A. Mobasheri [et al.] // Adv. Anat. Embryol. Cell Biol. - 2008. - Vol. 200, № 1. - P. 1-84.
6. Glucose Enhances Aggrecan Expression in Chondrocytes Via the PKC $\alpha / \mathrm{p} 38-m i R 141-3 p$ Signaling Pathway / T. J. Wu [et al.] // J Cell Physiol. - 2018. Vol. 233, № 9. - P. 6878-6887. - DOI: https://doi.org/ $10.1002 /$ jcp. 26451 .

7. Tankyrase Inhibition Preserves Osteoarthritic Cartilage by Coordinating Cartilage Matrix Anabolism Via Effects on SOX9 PARylation / S. Kim [et al.] // Nat ComMun. - 2019. - Vol. 10, № 1. - P. 4898. - DOI: https:/ /doi.org/10.1038/s41467-019-12910-2.

\section{REFERENCES}

1. Sovetnikov N.N., Kalsin V.A., Konopliannikov M.A., et al. Kletochnye tekhnologii i tkanevaya inzheneriya $\mathrm{v}$ lechenii defektov sustavnoi poverkhnosti. Klinicheskaya praktika, 2013, vol. 1, no. 13, pp. 52-66.

2. Shi Y., Hu X., Cheng J., et al. A Small Molecule Promotes Cartilage Extracellular Matrix Generation and Inhibits Osteoarthritis Development. Nat СомMиn., 2019, vol. 10, no. 1, p. 1914. DOI: https://doi.org/10.1038/ s41467-019-09839-x

3. Aiello F.C., Trovato F.M., Szychlinska M.A. Molecular Links Between Diabetes and Osteoarthritis: the Role of Physical Activity. Curr Diabetes Rev., 2017 , vol. 13 , no. 1 , pp. 50-58. DOI: https://doi.org/ 10.2174/1573399812666151123104352.

4. Akkiraju H., Nohe A. Role of Chondrocytes in Cartilage Formation, Progression of Osteoarthritis and Cartilage Regeneration. J Dev Biol., 2015, vol. 3, no. 4, pp. 177-192. DOI: https://doi.org/10.3390/jdb3040177.

5. Mobasheri A., Bondy C.A., Moley K., et al. Facilitative Glucose Transporters in Articular Chondrocytes. Expression, Distribution and Functional Regulation of GLUT Isoforms by Hypoxia, Hypoxia Mimetics, Growth Factors and Pro-inflammatory Cytokines. Adv. Anat. Embryol. Cell Biol., 2008, vol. 200, no. 1, pp. 1-84.

6. Wu T.J., Fong Y.C., Lin C.Y., et al. Glucose Enhances Aggrecan Expression in Chondrocytes via the PKC $\alpha / \mathrm{p} 38$-miR141-3p Signaling Pathway. J Cell Physiol., 2018, vol. 233, no. 9, pp. 6878-6887. DOI: https://doi.org/10.1002/jcp.26451.

7. Kim S., Han S., Kim Y., et al. Tankyrase Inhibition Preserves Osteoarthritic Cartilage by Coordinating Cartilage Matrix Anabolism Via Effects on SOX9 PARylation. Nat CомMun., 2019, vol. 10, no. 1, pp. 4898. DOI: https://doi.org/10.1038/s41467-019-12910-2. 


\section{Information About the Authors}

Sergey R. Baranov, Student, Department of Bioengineering and Bioinformatics, Volgograd State University, Prosp. Universitetsky, 100, 400062 Volgograd, Russian Federation, bsr140900@gmail.com

Lyudmila V. Derevshchikova, Student, Department of Bioengineering and Bioinformatics, Volgograd State University, Prosp. Universitetsky, 100, 400062 Volgograd, Russian Federation, derewshikowa2017@yandex.ru

Alina F. Samitova, Student, Department of Bioengineering and Bioinformatics, Volgograd State University, Prosp. Universitetsky, 100, 400062 Volgograd, Russian Federation, alinasamitova@mail.ru

Pavel A. Krylov, Candidate of Sciences (Biology), Associate Professor, Department of Bioengineering and Bioinformatics, Volgograd State University, Prosp. Universitetsky, 100, 400062 Volgograd, Russian Federation, krylov.pavel@volsu.ru

\section{Информация об авторах}

Сергей Романович Баранов, студент кафедры биоинженерии и биоинформатики, Волгоградский государственный университет, просп. Университетский, 100, 400062 г. Волгоград, Российская Федерация, bsr140900@gmail.com

Людмила Владимировна Деревщикова, студент кафедры биоинженерии и биоинформатики, Волгоградский государственный университет, просп. Университетский, 100, 400062 г. Волгоград, Российская Федерация, derewshikowa2017@yandex.ru

Алина Фаритовна Самитова, студент кафедры биоинженерии и биоинформатики, Волгоградский государственный университет, просп. Университетский, 100, 400062 г. Волгоград, Российская Федерация, alinasamitova@mail.ru

Павел Андреевич Крылов, кандидат биологических наук, доцент кафедры биоинженерии и биоинформатики, Волгоградский государственный университет, просп. Университетский, 100, 400062 г. Волгоград, Российская Федерация, krylov.pavel@volsu.ru 